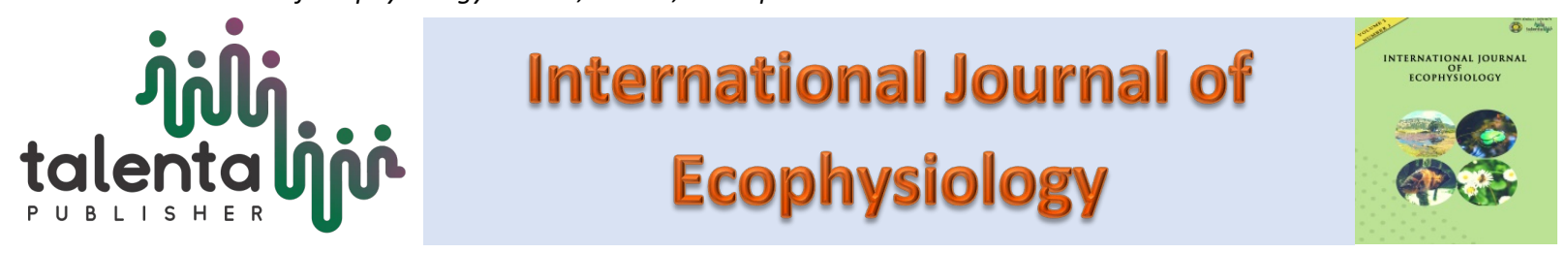

\title{
Karyotype and Growth Analysis of UV-induced Soybean (Glycine max L.)
}

\section{Elimasni, Rani Ernita Limbong, and Isnaini Nurwahyuni}

Department of Biology, Faculty of Mathematics and Natural Sciences, Universitas Sumatera Utara, Medan, North Sumatra 20155, Indonesia

\begin{abstract}
Karyotype and growth analysis of Soybean (Glycine max L.) after exposed to Ultraviolet light had been done. The objective of this research was to investigate karyotype design and vegetative growth of soybean induced with UV light. The experiment was Completely Randomized Designed with 2 treatment factors. The first factor was Ultraviolet light by 3 levels: 10, 20 and 30 Watt and the second was the length of UV exposure by 3 levels: 5, 10, and 15 minutes. Each treatment was replicated 2 times and the plant that was not exposed to UV used as control. The karyotype was observed by squash method. The results showed that the intensity and duration of UV light has no effect on the number of chromosomes but the light has effect on the number of chromosomes type. Statistical analysis showed that the increase in UV energy up to 30 Watt and time exposure of 15 minutes, caused the increase on height, number of leaves, flowers, the fresh and dry weight of plant, and chlorophyll concentration compared to untreated plants.
\end{abstract}

Keyword: Chromosome, Growth, Karyotype, Soybean, UV

Received 6 June, 2020 | Revised 23 July, 2020 | Accepted 22 August, 2020

\section{Introduction}

Soybeans are one of the most widely consumed plant sources of protein in Indonesia compared to milk, meat and others which are intensively harvested as important agricultural crops to fulfill the national demand on soybean supply [1]. The consumption of foodstuffs derived from legumes, especially soybeans for the Indonesian people in the future is expected to continue to increase. Majority or $70 \%$ of soybean supply in Indonesia were made into tofu and tempeh while $30 \%$ for other food types [2]. The national productivity of soybean was increased in the past 10 years between 2003-2012 resulted in 843.1 tons with annual increase of $3.75 \%$ per year [3]. However, the increased productivity still not balance with the intense consumption of

*Corresponding author at: Jl. Bioteknologi No. 1 Kampus Univ. Sumatera Utara, Padang Bulan, Medan, Indonesia 
soybean product in Indonesia with $60 \%$ of Indonesia's soybean consumption was imported during 2012 - 2016 [4].

One of the efforts to increase soybean production is through plant breeding. Plant breeding can be conducted in both conventional and non-conventional method. Conventional breeding includes hybridization, selection and introduction while non-conventional breeding may be approached by mutation or plant mutation breeding. Mutation can be classified into physical, chemical and biological technique. Physical mutations are mutations caused by physical factors such as $\mathrm{X}$ rays, gamma rays, and ultraviolet (UV) rays [5]. The utilization of UV in plant breeding has been widely used, commonly by exposing the irraditation below $280 \mathrm{~nm}$ (UV-B). Radiation within this wavelength can be absorbed by both purines and primidines as the backbone of DNA which may alter the structure of genes by forming covalent bonds or thymine dimers in random events [6].

Physical and chemical disorders that occur in cells may cause damage to chromosomes or change the number of chromosomes. The number of chromosomes in one type of organism is usually fixed, but the presence of external factors such as radioactive irradiation, high temperatures and mutagenic substances such as colchicine, will cause variations in the number and types of chromosomes [7, 8]. The description of the chromosomes of an individual is called a karyotype, which is useful for identifying certain abnormalities in chromosomes. This study then aims to determine the karyotype of soybean plants induced by UV as well as to produce soybean variant with improved growth and physiology.

\section{Materials and Methods}

\section{Experimental design}

This study follows the completely randomized factorial design with two factors namely factor 1 consisted of UV intensity of 10, 20, and 30 Watt with treatment code as I1, I2, I3, respectively, while factor 2 consisted of duration of UV exposure of 5, 10, and 15 minutes with treatment code as D1, D2, D3, respectively.

\section{UV exposure to soybean seedling}

The soybean (Glycine $\max$ L.) used in this study was a variety of Anjasmoro obtained from Sang Hyang Seri (SHS), Tanjung Morawa, Medan. Soybean seeds were washed under flowing tap water, cleansed, and air-dried. The seeds were then placed into plastic cup filled with immersed cotton plugs and grown until sprouts. Soybean sprouts were exposed to UV-B lamp inside a box following the desired treatments and placed into a dark box for $24 \mathrm{hr}$. Soybean sprouts were then planted into polybag filled with topsoil, sand, and compost in a ratio of 1:1:1. 
Daily watering and sunlight exposure of 12 day/ 12 night time was maintained in the greenhouse. The growth performance was observed 2 days after planting and continued weekly until reaching generative stage.

\section{Chromosome observation}

Root of 6-days old soybean sprouts were removed for microscope examination. The roots were cut into $\pm 1 \mathrm{~cm}$ fragments and immersed in 45\% acetic acid solution and stored in the refrigerator for 15-30 minutes. Root fragments were rinsed with distilled water thrice and hydrolyzed with $1 \mathrm{M} \mathrm{HCl}$, then heated at $30 \mathrm{oC}$ for 30 seconds. The root fragments were immersed in acetocarmin staining solution (a mixture of 1 gram of carmin with $100 \mathrm{ml}$ of acetic acid), left for 60 minutes, removed and placed on a glass slide. The remaining color is absorbed with a tissue, then dripped with canada balm and covered with a cover glass. The root fragments are squeezed gently to crush the roots. The roots were observed under a microscope from the smallest to the greatest magnification to see which cells have clear chromosomes. The cell was photographed at $1000 \times$ magnification, and the image was printed. The counting of the number, measurement and arrangement of chromosomes was done manually with the aid of Photoshop CS program [9].

\section{Data analysis}

\section{Plant growth}

The plant growth of UV-induced soybean was assessed through following parameters, i.e plant height $(\mathrm{cm})$, number of leaves $(\mathrm{N})$, fresh weight $(\mathrm{g})$, biomass $(\mathrm{g})$, number of flowers $(\mathrm{N})$, chlorophyll content (mg/g), and flower initiation (day).

\section{Statistical test}

The numerical data of each treatment was tested for its significance using analysis of variance (ANOVA), followed with multiple comparison of each variable using Duncan's multiple range test (DMRT) at $\alpha=0.05$.

\section{Result and Discussion}

\section{Chromosomal characteristics of UV-induced soybean}

The effect of UV exposure to soybean (Glycine $\max$ L.) seeds resulted in the same number of chromosomes through all treatments, which was 40 chromosomes (2n) (Figure 1). Chromosomes are classified into two types, namely metacentric and submetacentric. Each treatment resulted in a different number of chromosome types than the control. UV exposure of 10 and 20 watts resulted in a decreased number of metacentric types and an increase in 
submetacentric types, while the 30 watt treatment showed an increasing metacentric and decreasing submetacentric types. This is probably due to the treatment of UV light as a mutagen which caused damage at the gene level, which causes changes in chromosome size and affects the type of chromosome.

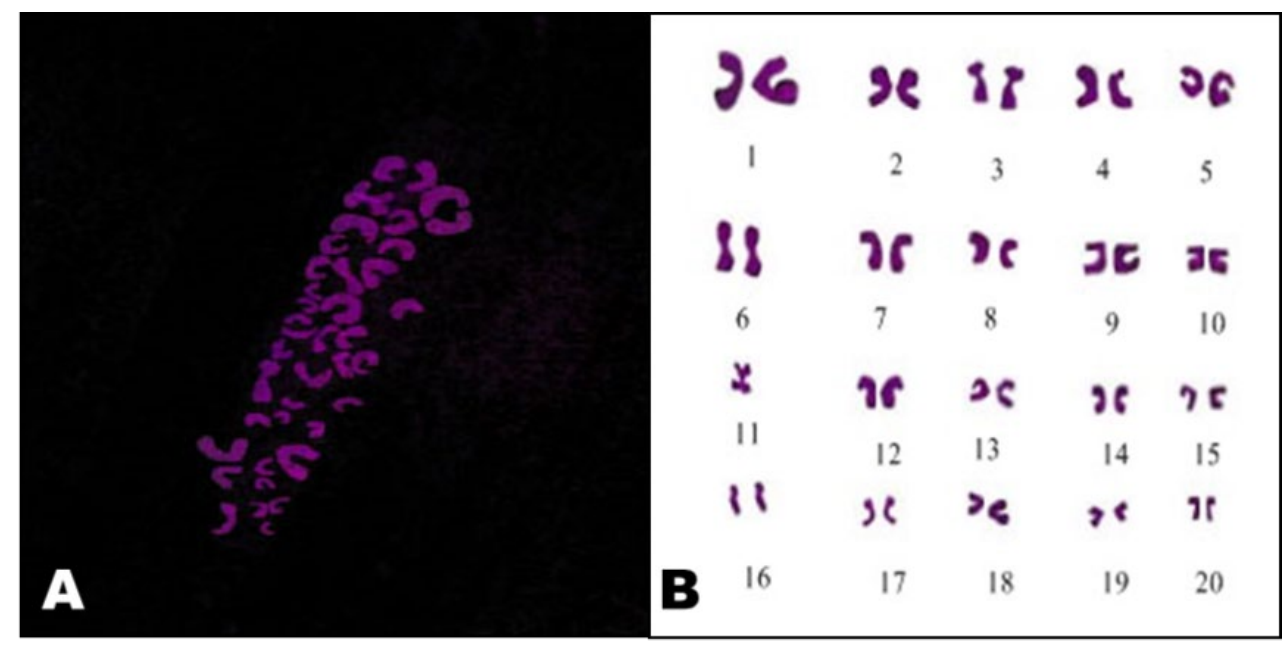

Figure 1 (A) Chromosomal image of UV-induced soybean. (B) Karyotyping of soybean

Table 1. Chromosome number and structure of UV-induced soybean

\begin{tabular}{cccc}
\hline \multirow{2}{*}{ Treatment } & Chromosome & \multicolumn{2}{c}{ Chromosome type } \\
\cline { 3 - 4 } & number (2n) & Metacentric & Submetacentric \\
\hline $\mathrm{I}_{0} \mathrm{D}_{0}$ & 40 & 15 & 5 \\
$\mathrm{I}_{1} \mathrm{D}_{1}$ & 40 & 17 & 3 \\
$\mathrm{I}_{1} \mathrm{D}_{2}$ & 40 & 16 & 4 \\
$\mathrm{I}_{1} \mathrm{D}_{3}$ & 40 & 14 & 6 \\
$\mathrm{I}_{2} \mathrm{D}_{1}$ & 40 & 17 & 3 \\
$\mathrm{I}_{2} \mathrm{D}_{2}$ & 40 & 17 & 3 \\
$\mathrm{I}_{2} \mathrm{D}_{3}$ & 40 & 14 & 6 \\
$\mathrm{I}_{3} \mathrm{D}_{1}$ & 40 & 13 & 7 \\
$\mathrm{I}_{3} \mathrm{D}_{2}$ & 40 & 13 & 7 \\
$\mathrm{I}_{3} \mathrm{D}_{3}$ & 40 & 14 & 6 \\
\hline
\end{tabular}

\section{Plant growth performance of UV-induced soybean}

The effect of UV irradiation to soybean growth performance is presented in Figure 2. Based on the statistical analyses, the growth performance of UV-induced soybean was not significantly affected in terms of plant height $(\mathrm{cm})$, fresh weight $(\mathrm{g})$, and dry weight or biomass $(\mathrm{g})$ but significantly different in the number of leaves (n), number of flowers (n), and chlorophyll content $(\mathrm{mg} / \mathrm{g}$ leaf $)(\mathrm{p}<0.05)$. In addition, the initiation day of soybean flowering was earlier 
from the control plant (Figure 3). The treatment of I2D2 gave the lowest growth performance consistently in all parameters.
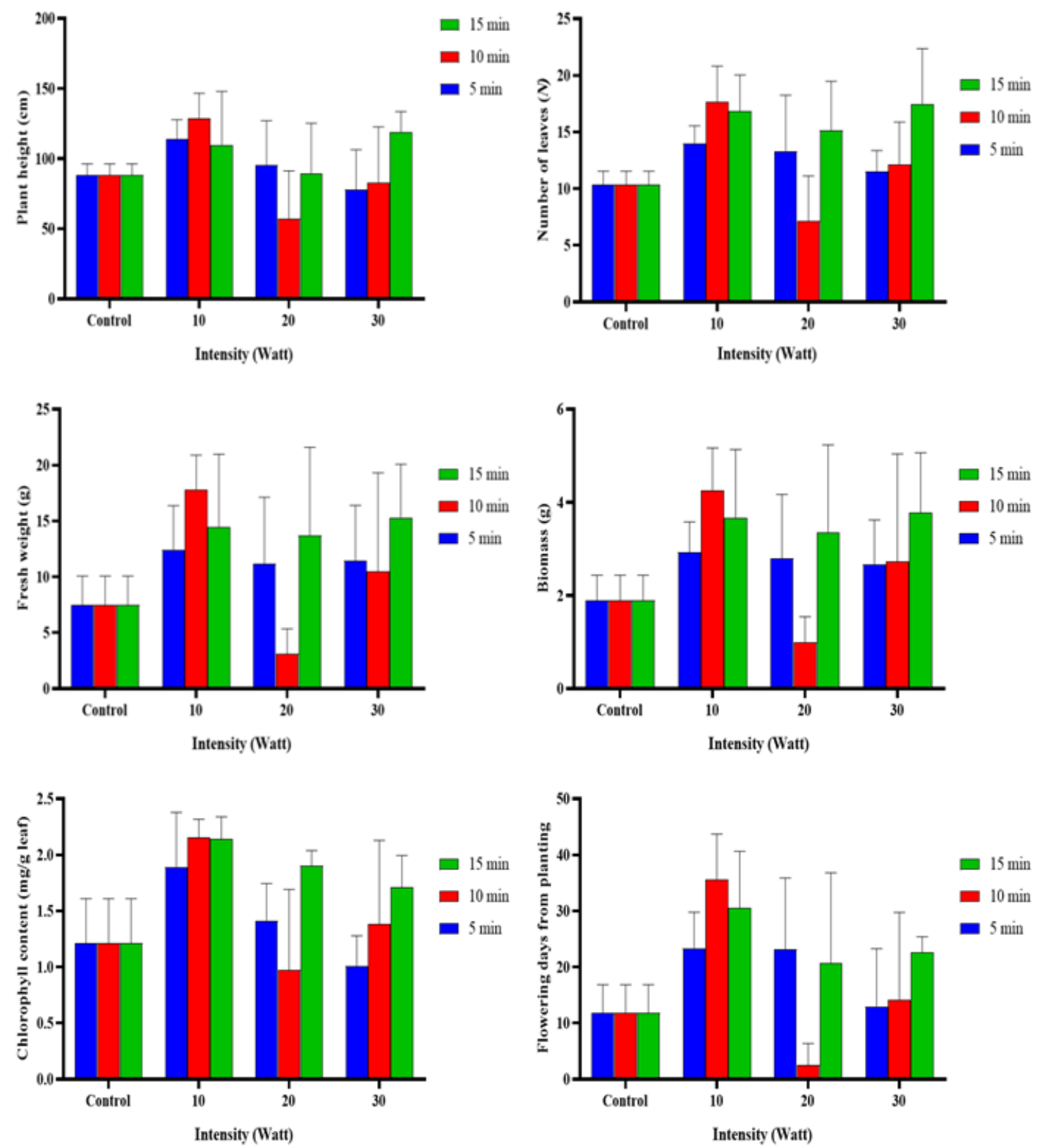

Figure 2. Plant growth performance of soybean plant Fibre and moisture content

The report on mutation breeding of soybean using UV-B exposure have been reported in several studies dating back from the past two decades because of the importance of intensity and quality of solar radiation to the soybean yield in the field [10-12]. However, the study is still limited to our most understanding, especially those originating from Indonesian region. In addition, the growth performance of other mutagenic agent, i.e Gamma ray was more popular and reported to induce changes in the growth habits of soybean. The dose of Gamma irradiation from 5 to 320 Gy was studied as the proper dose to induce physiological change in soybean with the lethal dose (LD50) of 314.78 Gy [13]. 


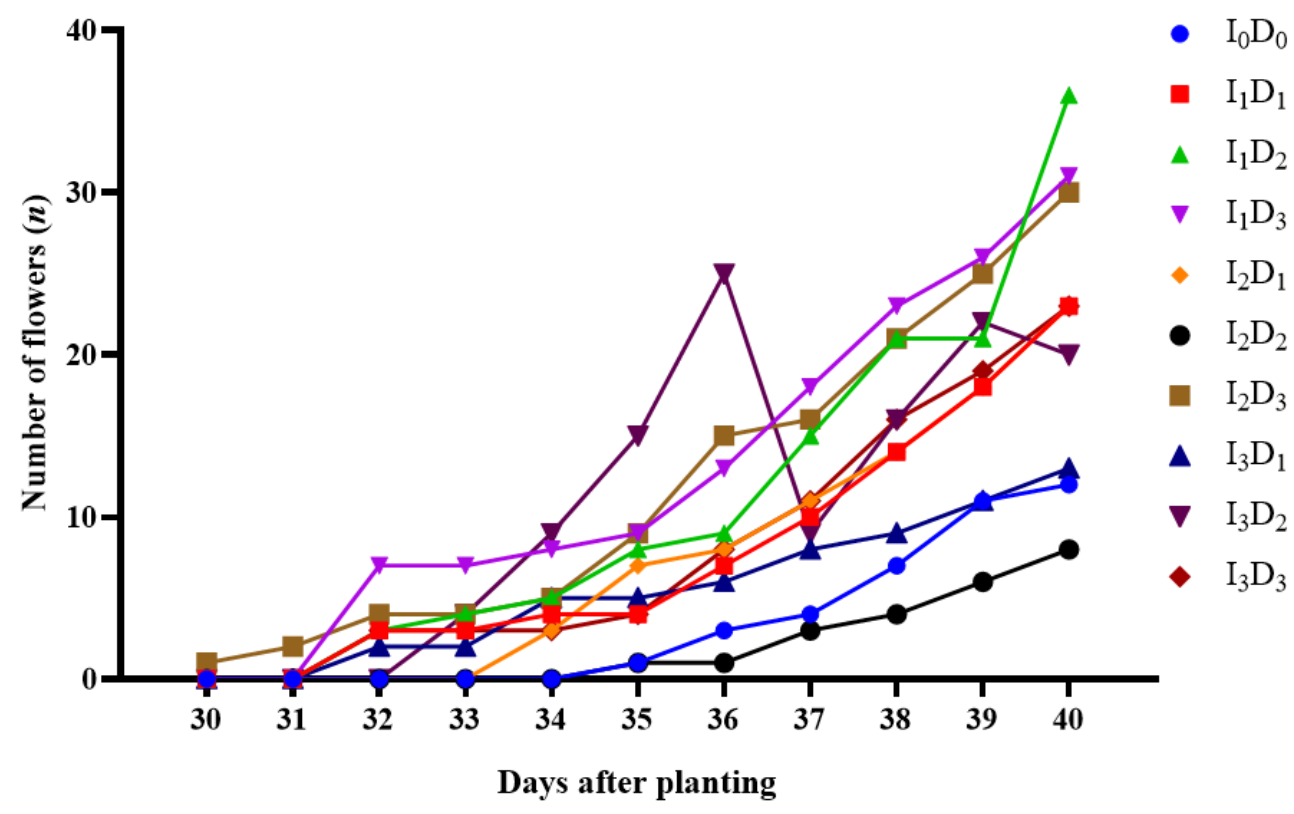

Figure 3. The effect of UV irradiation to the number of flowers of soybean seedling

Meanwhile, Feng et al [14] supported our results by reporting the significant alteration and change of the flowering time in some soybean cultivars. However, their study reported a decrease of chlorophyll $\mathrm{a} / \mathrm{b}$ content and total leaf number as indications to the decrease growth performance of the UV-induced soybeans which contraindicative of UV-B mutational effects. In contrary, previous study on an enhanced UV-B radiation to soybean based on field trials decreased the average biomass of 10 soybean cultivars by $24.2 \%$ which were different from our finding [15]. The difference may be explained by the use of different cultivars or strains which exhibited different tolerance and initial growth performance to UV-B irradiation under different duration of exposure as well.

A more recent study of 2-year field trial on three soybean cultivars namely Hai339 (H339), Heinong35 (HN35) and Kennong18 (KN18) from Chinese region revealed that a 40 Watt UV-B irradiation has decreased the seed size of soybean cultivars up to $12.3 \%$ [16]. Although our study on using three different UV-B doses at 10, 20, and 30 Watt did not affect the cytogenetics or chromosome profile of soybean seedlings, some growth traits were significantly enhanced from the UV-B exposure but only towards its vegetative phase. More investigations are needed to signify the whole mutational effect of UV-B to soybean seedlings based on the field trial until reaching its productivity phase or pod production which will emphasize their benefits on agronomic traits.

\section{Conclusion}

From the results of our study about UV-B irradiation effect to soybean seedlings, it can be concluded that different physiological changes was shown by the different treated plants 
following the intensity $(10,20,30$ Watt) and duration (10, 15, 20 minute) of exposure. The mutation did not affect on the number of chromosomes or karyotyping although gave a different proportion of metacentric and submetacentric chromosomes among treated plants. The UV-B irradiation significantly affected the growth performance of UV-induced soybean regarding the plant height $(\mathrm{cm})$, fresh weight $(\mathrm{g})$, and dry weight or biomass $(\mathrm{g})$ but not in the number of leaves (n), number of flowers (n), and chlorophyll content (mg/g leaf).

\section{REFERENCES}

[1] D. Wahyudi, L. Hapsari and Sundari, "RAPD Analysis for Genetic Variability Detection of Mutant Soybean (Glycine max (L.) Merr)," Journal of Tropical Biodiversity and Biotechnology, vol. 5, no. 1, pp. 68 - 77, 2020.

[2] E. Susilowati, R. Oktaviani, B. Arifin and Y. Arkeman, "The Decrease of Production of Indonesian Soybean and Efforts to Ensure the Certainty of the Vegetable Protein Supply: A Literature Review," International Journal of Technology and Business Management, vol. 9, no. 1, pp. 1 - 5, 2013.

[3] M. S. Poerwoko, N. Sjamsijah, K. Hariyono and Slameto, "The Performance of Soybean Genotypes as the Result of Hybridization on Leaf Rust Disease," Bioscience Research, vol. 15, no. 3, pp. 2019 - 2028, 2018.

[4] S. S. Wulandari, "Indonesian Government Policy in Protecting Local Farmers from The Threat of U.S. Soybean Imports 2012 - 2016," Student Online Journal (JOM) Faculty of Social and Political Sciences, vol. 4, pp. 1 - 15, 2016.

[5] Y. Oladosu, M. Y. Rafii, N. Abdullah, G. Hussin, A. Ramli, H. A. Rahim, G. Miah and M. Usman, "Principle and Application of Plant Mutagenesis in Crop Improvement: A Review," vol. 30, no. 1, pp. 1 - 16, 2015.

[6] M. H. Khan and S. D. Tyagi, "A Review on Induced Mutagenesis in Soybean," Journal of Cereals and Oilseeds, vol. 4, no. 2, pp. 19 - 25,

[7] S. S. Gill, N. A. Anjum, R. Gill, M. Jha and N. Tuteja, "DNA Damage and Repair in Plants under Ultraviolet and Ionizing Radiations," The Scientific World Journal, vol. 2015, no. $250158,2015$.

[8] G. C. Cannon, L. A. Hendrick and S. Heinhorst, "Repair Mechanisms of UV-induced DNA Damage in Soybean Chloroplasts," Plant Physiology, vol. 133, no. 4, pp. 1420 - 1428, 2003.

[9] L. Shi, T. Zhu, M. Morgante, J. A. Rafalski and P. Kelm, "Soybean Chromosome Painting: A Strategy for Somatic Cytogenetics," Journal of Heredity, vol. 87, no. 4, pp. 308 - 313, 1996.

[10] H. Teramura, "Effects of Ultraviolet-B Radiation on the Growth and Yield of Crop Plants," Physiologia Plantarum, vol. 58, pp. 415 - 427, 1983.

[11] J. E. Board and B. G. Harville, "Growth Dynamics during the Vegetative Period Affects Yield of Narrow-Row, Late-planted Soybean," Agronomy Journal, vol. 88, pp. 567 - 572, 1996.

[12] Liu, C. Wang, J. Jin, J. D. Liu, Q. Y. Zhang and X. B. Liu, "Responses of Soybean and Other Plants to Enhanced UV-B Radiation," Soybean Science, vol. 28, pp. 1097 - 1102, 2009. 
[13] F. Kusmiyati, Sutarno, M. G. A. Sas and B. Herwibawa, "Mutagenic Effects of Gamma Rays on Soybean (Glycine max L.) Germination and Seedlings, "IOP Conference Series: Earth and Environmental Science, vol. 102, no. 012059, 2017.

[14] H. Y. Feng, L. Z. An, S. J. Xu, W. Y. Qiang, T. Chen and X. L. Wang, "Effect of Enhanced Ultraviolet-B Radiation on Growth, Development, Pigments and Yield of Soybean (Glycine max (L.) Merr.)," Acta Agronomica Sinica, vol. 27, pp. 319 - 323, 2001.

[15] H. Y. Feng, T. Chen, S. J. Xu, L. Z. An, W. Y. Qiang, M. X. Zhang and X. L. Wang, "Effect of Enhanced UV-B Radiation on Growth, Yield and Stable Carbon Isotope Composition in Glycine max Cultivars," Acta Botanica Sinica, vol. 43, pp. 709 - 713, 2001.

[16] Liu, X. Liu, Y-S. Li and S. J. Herbert, "Effects of Enhanced UV-B Radiation on Seed Growth Characteristics and Yield Components in Soybean," Field Crops Research, vol. 154, pp. $158-163,2013$. 